\title{
Studies on Human Platelet Gangliosides
}

\author{
Aaron J. Marcus, Harris L. Ullman, and Lenore B. Safier \\ From the Hematology Section, New York Veterans Administration Hospital, \\ New York 10010, and the Department of Medicine, New York Hospital-Cornell \\ Medical Center, New York 10021
}

\begin{abstract}
A в S T R A C T Gangliosides, glycosphingolipids which contain sialic acid, were studied in human platelets. They represented $0.5 \%$ of the platelet lipids and accounted for $6 \%$ of the total neuraminic acid content of platelets. Three major ganglioside fractions were identified and characterized. Ganglioside I was hematoside $\left(\mathrm{G}_{6}\right)$ and comprised $92 \%$ of the platelet gangliosides. It contained glucose, galactose, and sialic acid in molar ratios of $1: 1: 1$ and no hexosamine. The major fatty acid was behenate $(22: 0)$. Ganglioside I was also identified in isolated platelet granules and membranes. Ganglioside II (5\%) contained glucose, galactose, sialic acid, and hexosamines (molar ratios $1: 2: 1: 1$ ). The hexosamines were glucosamine $(72 \%)$ and galactosamine $(28 \%)$. It was therefore designated as ganglioside lacto$\mathrm{N}$-neotetraose. Ganglioside III ( $2 \%)$ contained disialosyllactosyl ceramide $\left(\mathrm{G}_{3 \mathrm{~s}}\right)$ as well as two other gangliosides which could not be precisely characterized. Gangliosides I, II, and III were susceptible to the action of Clostridium perfringens neuraminidase as evidenced by full recovery of sialic acid in its free form after incubation. Neutral platelet glycolipids were qualitatively examined by thinlayer chromatography. The major component was lactosyl ceramide.
\end{abstract}

Interactions of gangliosides I and III and serotonin $-{ }^{14} \mathrm{C}$ were examined in an equilibrium dialysis system at $4^{\circ} \mathrm{C}$. The gangliosides bound serotonin ${ }^{14} \mathrm{C}$ in relatively small quantities, whereas control lipids were negative. The binding was essentially unchanged by reverse dialysis, ultracentrifugation and subsequent thin-layer chromatography. The results are comparable to the previously observed nonmetabolic interactions between whole platelets and serotonin in the cold. It is suggested that the orientation and specific distribution of platelet membrane glycolipids may be important determinants of the unique surface properties of platelets.

Received for publication 10 April 1972 and in recised form 2 June 1972.

\section{INTRODUCTION}

Gangliosides are glycosphingolipids which by definition contain one or more residues of acylated neuraminic acid per molecule. Additional components are a sphingosine base, fatty acids, hexoses, and, often, hexosamines. Gangliosides were first discovered in brain and have now been identified in many extraneural tissues $(1,2)$. The function of gangliosides is unknown, although several interesting physiological roles have been postulated (3). Among these are the binding of 5-hydroxytryptamine (5-HT, serotonin $)^{1}$ and univalent cations such as $\mathrm{Na}^{+}$ and $\mathrm{K}^{+}$, as well as divalent cations such as $\mathrm{Ca}^{++}$.

Calcium plays an important but as yet incompletely defined role in platelet function and, as in other tissues (4), may be involved in platelet adenosine $3^{\prime}, 5^{\prime}$-monophosphate (cyclic AMP) metabolism. In addition, the unique avidity of platelets for serotonin remains unexplained. Finally, it is now becoming apparent that the surface characteristics of cell membranes may be in large part determined by glycolipids and glycoproteins $(5,6)$.

The purpose of this study was to examine human platelets for the presence of gangliosides. The gangliosides identified were characterized biochemically and their interactions with serotonin were examined in an equilibrium dialysis system.

\section{METHODS}

Preparation of platclets. A total of $2846 \mathrm{U}$ of platelet concentrates ( $1579 \mathrm{~g}$ wet weight of platelets) were processed at periodic intervals. These were donor packs, about $12 \mathrm{hr}$

${ }^{1}$ Abbreviations used in this paper: cyclic AMP, adenosine $3^{\prime}, 5^{\prime}$-monophosphate; EGS, ethylene glycol succinate; $\mathrm{G}_{3.1}$, disialosyllactosyl ceramide; $\mathrm{G}_{\mathrm{D1a}}, \mathrm{G}_{3}$, sialosylgalactosyl- $N$ acetylgalactosaminyl (sialosyl) lactosyl ceramide; $\mathrm{G}_{\mathrm{L} \text { NnT }} 1$ (N A N A), sialosylgalactosyl-N-acetylglucosaminyllactosyl ceramide; GM1, galactosyl- $N$-acetylgalactosaminyl-( sialosyl) lactosyl ceramide; GLC, gas-liquid chromatography: $\mathrm{G}_{\mathrm{f}}$, $\mathrm{G}_{\mathrm{M} 3}$, sialosyllactosyl ceramide, hematoside; 5-HT, 5-hydroxytryptamine, serotonin; NANA, $n$-acetyl neuraminic acid; TBA, thiobarbituric acid; TLC, thin-layer chromatography; TMS, trimethylsilyl. 
old and maintained under sterile conditions. Approximately $3 \mathrm{U}$ were combined in each of eight $50-\mathrm{ml}$ conical polypropylene centrifuge tubes at one time. The tubes were centrifuged at $5,000 \mathrm{~g}$ for $20 \mathrm{~min}\left(18^{\circ} \mathrm{C}\right)$. The pellets were pooled and washed three times by resuspension in isotonic saline. The washed platelets were stored at $-20^{\circ} \mathrm{C}$ until immediately before lipid extraction, whereupon the tube was smashed with a hammer, releasing the frozen pellet. If red cell contamination was present the area was sliced off the frozen pellet with a scalpel blade. The washing procedure was monitored by phase microscopy. The final platelet preparations did not contain more than one erythrocyte or leukocyte per 50 high power fields. In general the processed platelets contained no contamination with other cells. Platelet membranes and granules were prepared as previously described (7).

Sialic acid determinations. The total sialic acid content of platelets was determined first. Washed platelets were hydrolyzed in $0.05 \mathrm{~N} \mathrm{H}_{2} \mathrm{SO}_{4}$ and the hydrolysates assayed by the thiobarbituric acid (TBA) method of Warren (8) and the resorcinol technique devised by Svennerholm (9). Measurements were carried out directly, as well as after purification on ion exchange columns prepared with Dowex $50\left(\mathrm{H}^{+}\right)$and Dowex 1 (acetate form) $)^{2}(9)$. The column procedure was performed in order to remove interfering substances such as hexoses.

Quantification of lipid-bound sialic acid was dependent on the state of purification of the gangliosides. Relatively pure preparations could be assayed directly by the resorcinol method (10) with spectrophotometric readings at $580 \mathrm{~m} \mu$. When crude samples were under study purification was necessary by thin-layer chromatography (TLC) on silica gel $\mathrm{G}$ plates prepared with $1 \%$ sodium borate solution in place of water (11). This was followed by resorcinol assay directly on the positively identified spots which were scraped off the plate $(12,13)$. In order to facilitate identification of spots containing small amounts of ganglioside a modification of the Suzuki $(12,13)$ procedure suggested by MacMillan and Wherrett (14) was employed. This was especially useful in estimating quantitative recoveries during the course of purification. Alternatively the Svennerholm column procedure (9) could also be used for quantifying the ganglioside content of crude lipid extracts. However, flocculent material which appeared in the lipid hydrolysates interfered with column filtration and made the procedure less convenient.

There were specific indications for the use of correction factors during spectrophotometry. When evaluating total platelet sialic acid by the resorcinol method correction for hexoses by reading at $450 \mathrm{~m} \mu$ (15) was required. In the case of lipids which were separated on borate TLC plates correction factors were unnecessary. When whole platelets were studied after column purification a correction factor for ribose esters was required because these sugars emerged from the column along with sialic acid. Ribose correction was unnecessary when lipid extracts were purified by the column procedure. In the TBA method on whole platelets a correction factor at $532 \mathrm{~m} \mu$ was not required. Unless the aforementioned precautions were taken values obtained for sialic acid content were not accurately reproducible. In the course of ganglioside purification by partitioning by the method of Folch, Lees, and Sloane Stanley (16), material giving false positive colors in the resorcinol assay was occasionally encountered. In such instances it was helpful to compare a spectrum of these chromogens from 440 to 600

\footnotetext{
${ }^{2}$ Dow Chemical Co., Midland, Mich.
}

$\mathrm{m} \mu$ with that of an $n$-acetyl neuraminic acid (NANA) standard.

Preparation of platelet lipid extracts. Thawed platelets were extracted in a Waring Blendor ${ }^{3}$ at low speed in 4-6 $\mathrm{ml}$ of cold acetone per $\mathrm{g}$ wet weight at $4^{\circ} \mathrm{C}$. The mixture was filtered through a sintered glass funnel (medium porosity). Material remaining on the filter was reextracted twice in the same manner. The acetone powder was dried, weighed, and extracted twice with chloroform-methanol $1: 1(20 \mathrm{ml} / \mathrm{g}$ of powder). This was done for 30 -min periods at room temperature with vigorous magnetic stirring. Finally the dried powder was extracted twice with chloroform-methanol $1: 2(10 \mathrm{ml} / \mathrm{g}$ powder) for $30 \mathrm{~min}$ in a similar manner. The combined chloroform-methanol extracts were evaporated to dryness in a rotary evaporator, redissolved in a total of $45 \mathrm{ml}$ of chloroform-methanol $2: 1$, and transferred to $50-\mathrm{ml}$ conical tubes. The tubes were centrifuged at $600 \mathrm{~g}$ for $15 \mathrm{~min}\left(10^{\circ} \mathrm{C}\right)$ in order to remove any remaining insoluble residue. The clear supernates were transferred to a large glass-stoppered graduated cylinder and made up to a volume of chloroform-methanol 2:1 corresponding to 35 $\mathrm{ml} / \mathrm{g}$ of original acetone powder (17).

It was necessary to carry out the partitioning procedure (16) according to the particular ganglioside under study. Since the use of salts in the partitioning mixture resulted in a loss of hematoside into the lower phase, partitioning was thenceforth carried out with deionized doubly distilled water. The lower phases were washed twice with "pure solvents upper phase" without salt. This maneuver resulted in complete recovery of hematoside, as evidenced by its absence from the lower phase. This was verified by TLC of concentrates derived from the lower phase. Partitioning specifically for more polar gangliosides was carried out with $0.1 \mathrm{M}$ $\mathrm{KCl}$ which was also included in the wash. In all instances separation of phases was facilitated by centrifugation, which also served to "compress" the "interfacial fluff" which appeared during the water partitioning procedure.

The upper phases were combined, evaporated to a small volume $(1 \mathrm{ml})$, and $20 \mathrm{ml}$ of methanol was added. Saponification was carried out by adding $1.3 \mathrm{ml}$ of $2 \mathrm{~N} \mathrm{NaOH}$ (final normality $0.1 \mathrm{~N}$ ) and incubating at $37^{\circ} \mathrm{C}$ for $3-4 \mathrm{hr}$ with occasional agitation. This procedure removed glycerol phosphatides which may have entered the upper phase during the partitioning step. It did not, however, remove traces of sphingomyelin, which were subsequently separated by TLC. The saponification mixture was extracted three times with $10-\mathrm{ml}$ portions of hexane which removed methyl esters of phospholipid fatty acids. The upper hexane layer was discarded and the lower layer evaporated to $2 \mathrm{ml}$ and transferred to dialysis bags in an additional $6 \mathrm{ml}$ of water. The dialysis bags had previously been boiled in three changes of distilled water. Dialysis was carried out against 6 liters of water $\left(4^{\circ} \mathrm{C}\right)$ for at least $48 \mathrm{hr}$, during which time three changes were made. Finally the dialyzed material was lyophilized and stored at $-20^{\circ} \mathrm{C}$.

Thin-layer chromatography. The basic TLC techniques were those previously described (18); however, in these studies the plates were coated with silica gel $\mathrm{HR}^{*}$ to a thickness of $500 \mu$ unless otherwise stated. Recovery of eluted samples was maximal with this coating material $(98-100 \%)$. In all instances the plates were washed twice in developing solvents before activation. The two step TLC

${ }^{3}$ Waring Products Div., Dynamics Corp. of America, New Hartford, Conn.

- Brinkmann Instruments, Inc., Westbury, N. Y. and Analtech, Inc., Wilmington, Del. (pre-coated). 
procedure devised by Ledeen, Salsman, and Cabrera (19) was used. The solvent system was chloroform-methanol-2.5 $\mathrm{N}$ ammonium hydroxide $(60: 40: 9)$. At the completion of the initial run the plate was dried under a stream of nitrogen for 45-60 min. After drying, the plate was replaced in a tank containing a freshly prepared mixture of the same solvent. Solvent-containing tanks were preequilibrated for $1 \mathrm{hr}$ and plates were activated at $110^{\circ} \mathrm{C}$ for $60 \mathrm{~min}$ followed by cooling in a desiccator for $20 \mathrm{~min}$ before use. When TLC plates were coated with silica gel $G$, the separations were adequate but recoveries after elution were quantitatively low.

At the completion of a chromatographic run the plates were dried under a stream of nitrogen. In preparative procedures the plates were sprayed with a solution of bromthymol blue in ammonia (20). The identified ganglioside bands were scraped from the plate and extracted three times with acetone, which removed most of the stain (20). Elution was then carried out using 5-10 $\mathrm{ml}$ of chloroform-methanolwater, 50:50:15 (freshly prepared) (19), and this was repeated twice. The combined eluates were taken to dryness and stored in the solid state at $-20^{\circ} \mathrm{C}$ before the next experimental procedure.

Platelet gangliosides were further identified by TLC using two additional solvent systems. Plates precoated with silica gel $\mathrm{G}$ were developed with either $n$-propanol-water $(7: 3)$ (21) or chloroform-methanol-water $(60: 35: 8)$ (21).

Gas-liquid chromatography (GLC). A Hewlett-Packard model $7620 \mathrm{~A}$ research chromatograph" equipped with a model $3370 \mathrm{~A}$ integrator was used. The detection system was of the flame ionization type. Circular glass columns, $6 \mathrm{ft}$ in overall length, with an internal diameter of 1 inch were employed. The carrier gas was prepurified nitrogen at an inflow rate of $30 \mathrm{~cm}^{3} / \mathrm{min}$.

Carbohydrate analyses by GLC were based on methods developed by Sweeley and Walker (22) and by Ledeen and associates (19). All preparative operations were carried out under cover of nitrogen. Eluates derived from TLC plates (0.2-0.4 $\mu$ moles of ganglioside) were placed in methanolysis tubes $^{6}(23)$ and $2 \mathrm{ml}$ of freshly prepared $0.5 \mathrm{~N}$ "instant methanolic $\mathrm{HCl}^{\prime}$ " were added. Hydrolysis was carried out under nitrogen for $23 \mathrm{hr}$ at $80^{\circ} \mathrm{C}$. After cooling the hydrolysates were extracted three times with $3-\mathrm{ml}$ portions of redistilled hexane. Each extraction mixture was centrifuged for $2 \mathrm{~min}$ at room temperature $(1600 \mathrm{~g})$ in order to sharply delineate the interface between the hexane and methanol layers. The hexane extracts were stored at $-20^{\circ} \mathrm{C}$ under nitrogen before fatty acid analyses. In order to prevent transformation of methyl galactosides into unidentifiable analogs and thus invalidate glucose-galactose ratios, 166.7 $\mathrm{mg}$ of silver acetate was added to the extracted hydrolysate as described by Windeler and Feldman (24). The tubes were evaporated under nitrogen, the sides rinsed with $0.5 \mathrm{ml}$ of methanol and redried. Finally the tubes were desiccated over $\mathrm{KOH}$ for $15 \mathrm{~min}$ in vacuo. Reacetylation of sialic acid and any hexosamine which was present was carried out as follows: A mixture of methanol-acetic anhydride (3:1) was added to the hydrolysates in $0.5-\mathrm{ml}$ amounts and the vortexed mixtures allowed to react under nitrogen for $24 \mathrm{hr}$ in the dark (22). An additional $1 \mathrm{ml}$ of methanol was added and the silver salts removed by filtration through sintered

${ }^{5}$ Hewlett-Packard Co., Palo Alto, Calif.

- Coleman-Delmar Glass Products Div., Perkin-Elmer Corp., Maywood, Ill.

${ }^{7}$ No. 18053A, Applied Science Laboratories Inc., State College, $\mathrm{Pa}$. glass of ultra-fine porosity. The filtrates were transferred to $15-\mathrm{ml}$ conical tubes with teflon-lined screw caps and evaporated to dryness. The sides of the tubes were washed in order to concentrate the material into the cone of the tube. After desiccation, trimethylsilyl (TMS) derivatives were prepared using 100-200 $\mu$ l of the reagent described by Carter and Gaver (25). The silyl reagents were evaporated and the derivatives taken up in hexane (19) to a final volume of $25 \mu \mathrm{l}$. GLC was carried out immediately after silylation on a Supelcoport ${ }^{8}$ column $(80 / 100$ mesh) coated with $3 \%$ OV $-1 .{ }^{\circ}$ The column was previously conditioned for 24-36 hr at $260^{\circ} \mathrm{C}$ under a nitrogen pressure of $50 \mathrm{psi}$.

Initial operating conditions were as follows: injection port $230^{\circ} \mathrm{C}$; column $160^{\circ} \mathrm{C}$; detector $300^{\circ} \mathrm{C}$. Flow rates through the detector were: hydrogen $30 \mathrm{~cm}^{3} / \mathrm{min}$; air $450 \mathrm{~cm}^{3} / \mathrm{min}$. The electrometer sensitivity range was at $10^{4}$ and dual columns were used at all times in order to compensate for bleeding of the stationary phase at high temperatures. Temperature programming was used in all carbohydrate analyses. Columns were held at $160^{\circ} \mathrm{C}$ for $15 \mathrm{~min}$ and programming was initiated at a rate of $2^{\circ} \mathrm{C}$ per min to a final temperature of $250^{\circ} \mathrm{C}$. In general, $1 \mu \mathrm{l}$ amounts containing the equivalent of $0.01-0.02 \mu$ moles of ganglioside were injected for each GLC run. Control samples consisted of TLC elution solvents which were carried through the entire procedure. These were essential since false positive peaks with retention times comparable to $\alpha$-glucose and other carbohydrates interfered with quantitative analysis of the ganglioside under study. This interference was not due to contaminants in the silica gel used for TI.C. Before GLC analyses of platelet gangliosides, qualitative and quantitative detector response was calibrated with the use of known glycolipid and carbohydrate standards. GLC analyses on any given hydrolysate were run in triplicate.

Fatty acid studies were carried out on polar columns consisting of Supelcoport ${ }^{10}(80 / 100$ mesh) coated with $14 \%$ ethylene glycol succinate (EGS). The initial column temperature was $165^{\circ} \mathrm{C}$ for $15 \mathrm{~min}$ with a program of $1^{\circ} \mathrm{C}$ per $\min$ to $200^{\circ} \mathrm{C}$. When the ganglioside in question showed a preponderance of short-chain fatty acids the initial temperature was reduced to $145^{\circ} \mathrm{C}$. Linearity of detector response to mass, and peak identification were verified as previously described $(26,18)$. When indicated, GLC was also carried out on a nonpolar column (Apiezon L). ${ }^{11}$ This was done to confirm the identity of questionable peaks (26). The hexane layers which were derived from the original methanolic hydrolysate were taken to dryness and concentrated to a volume of $20 \mu 1$. 2- to $4-\mu 1$ amounts containing the equivalent of $0.04 \mu$ moles of ganglioside were then subjected to GLC. As in the carbohydrate analyses, blank control samples were carried through the entire procedure for reasons comparable to those already mentioned. The necessity for blank controls has been cited by other laboratories (27).

Ncuraminidase cxperiments. Platelet gangliosides $(0.1-$ $0.2 \mu$ moles sialic acid) were incubated with $0.1 \mathrm{U}$ neuraminidase from Clostridium perfringens ${ }^{12}$ for $48-72 \mathrm{hr}$. The initial volume of the incubation mixture was $1 \mathrm{ml}$. At periodic intervals four additional $0.1 \mathrm{U}$ of enzyme were added to the mixture in $0.1 \mathrm{ml}$ portions of buffer (28). Calcium was not required for the reactions under study. At the end of the incubation period $0.1-\mathrm{ml}$ samples were

${ }^{8}$ Supelco, Inc., Bellefonte, $\mathrm{Pa}$.

- Applied Science Laboratories Inc., State College, Pa.

${ }^{10}$ Supelco, Inc., Bellefonte, $\mathrm{Pa}$.

${ }^{11}$ James G. Biddle Co., Plymouth Meeting, Pa.

${ }^{12}$ Type VI, Sigma Chemical Co., St. Louis, Mo. 
removed from the reaction mixture for assay of free sialic acid by the TBA method. The remaining material was extracted with 20 vol of chloroform-methanol $2: 1$, filtered, taken to dryness, and subjected to TLC.

Equilibrium dialysis experiments. For these studies 5hydroxytryptamine- $-3^{\prime}-{ }^{14} \mathrm{C}$ creatinine sulphate ${ }^{13}$ with a specific activity of $58 \mathrm{mCi} / \mathrm{mmole}$ was used. The radiochemical purity was $99 \%$ and the chemical purity verified by infra-red spectroscopy. ${ }^{13}$ Acrylic plastic equilibrium-type dialysis cells with an actual chamber capacity of $0.95 \mathrm{ml}$ on each side were employed. ${ }^{14}$ A moist, preboiled dialysis membrane was placed between the opposing sides. ${ }^{25}$ All procedures were carried out at $4^{\circ} \mathrm{C}$ with continuous gentle agitation. At given intervals $25-\mu 1$ samples were removed from both sides, transferred to scintillation vials containing $10 \mathrm{ml}$ of Bray's solution, and counted. ${ }^{16}$ The following materials were tested in the dialysis system; platelet gangliosides I and III, bovine kidney $\mathrm{G}_{3 \Delta}$ and $\mathrm{G}_{6}$ (2) (isolated in our laboratory), and

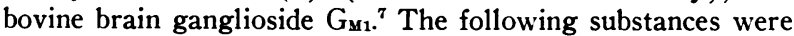
used as controls for comparison with gangliosides: platelet membrane lecithin, platelet membrane cholesterol, and egg lysolecithin. ${ }^{7}$ The lipids studied were used in a concentration range of 30-200 nmoles per $0.95 \mathrm{ml}$. The serotonin ${ }^{14} \mathrm{C}$ concentration was held at 20 nmoles per $0.95 \mathrm{ml}$ at the start of each experiment. The suspending media consisted of doubly distilled water or $0.1 \mathrm{M}$ sodium phosphate buffer, $\mathrm{pH} 7.4$ (29). In each experiment the radioactive 5-HT was dialyzed against the opposite chamber containing the suspending medium only as an equilibrium control. The serotonin $-{ }^{14} \mathrm{C}$ could be placed on the same or opposite side as the test substance, since results were identical in either case. The degree of binding was determined from the difference in counts between the two sides of the chamber after equilibrium was achieved $(24 \mathrm{hr})$. Results were expressed as moles of lipid required to bind one mole of serotonin $-{ }^{14} \mathrm{C}$. At the conclusion of some experiments the contents of the chamber containing the test substance (as well as the radioactive 5-HT controls) were subjected to ultracentrifugation in $0.8 \mathrm{ml}$ cellulose nitrate tubes at $248,755 \mathrm{~g}$ for $1 \mathrm{hr}$ $\left(3^{\circ} \mathrm{C}\right)$ in an $\mathrm{SW} 65 \mathrm{~L}$ rotor. Five successive $0.1-\mathrm{ml}$ fractions were aspirated, counted for radioactivity, and assayed for sialic acid. The contents of the bottom fraction from the ultracentrifuge tube were also identified by TLC. They were spotted on a silica gel G TLC plate along with standard ganglioside markers and samples of serotonin- ${ }^{14} \mathrm{C}$ as well as cold serotonin and developed in distilled water (30). The control lanes were stained with resorcinol and the cold serotonin lanes could be visualized grossly after they oxidized in air. The lanes in question were divided into eight portions based upon the staining reactions of the controls, scraped into counting vials containing $10 \mathrm{ml}$ of Aquasol, ${ }^{17}$ and counted. It was then possible to ascertain whether the radioactivity was still associated with the ganglioside removed from the dialysis chamber.

Other analytical procedures. Protein was measured as previously described (7). Lipid phosphorus determinations were carried out by the colorimetric method of Parker and Peterson (31). Glucose content of isolated gangliosides was measured colorimetrically as a check on the GLC quanti-

\footnotetext{
${ }^{13}$ Amersham/Searle Corp., Arlington Heights, Ill.

${ }_{14}$ Model 260, Bel-Art Products, Pequannock, N. J.

${ }^{15}$ No. 8-667-1, Fisher Scientific Company, Pittsburgh, Pa.

${ }^{16}$ Nuclear-Chicago Corporation, Des Plaines, Ill., Mark I.

${ }^{17}$ New England Nuclear Corp., Boston, Mass.
}

TABLE I

Sialic Acid Content of Whole Platelets by Four Methods*

\begin{tabular}{cccc}
\hline Method $\ddagger$ & Sample 18 & Sample 28 & Sample 3\| \\
\hline $\begin{array}{c}\text { Resorcinol, corrected } \\
\text { by dichromatic readings }\end{array}$ & 8.4 & 6.8 & 9.1 \\
$\quad 580$ and 450 m $\mu$ & & & \\
$\begin{array}{l}\text { Svennerholm column } \\
\text { procedure }\end{array}$ & 7.6 & 6.2 & 9.6 \\
$\begin{array}{l}\text { TBA method, uncorrected } \\
\text { TBA on column eluates, }\end{array}$ & 8.1 & 7.0 & 9.4 \\
$\quad$ uncorrected & 8.2 & 6.9 & 9.5 \\
\hline
\end{tabular}

* Micrograms NANA per milligram platelet protein.

$\ddagger$ For details, see section on Methods.

\$ Individual donors.

|| Pooled platelet concentrates from bank blood.

fications. The glucose oxidase method ${ }^{18}$ was employed (15) after hydrolysis of the sample with $2 \mathrm{~N} \mathrm{HCl} \mathrm{(32)} \mathrm{(3} \mathrm{hr} \mathrm{at}$ $100^{\circ} \mathrm{C}$ ) and neutralization with $\mathrm{NaOH}$ (33). The lower phases from the ganglioside extractions were examined for the presence of neutral glycolipids utilizing the techniques of Vance and Sweeley (34). All solvents were redistilled before use.

\section{RESULTS}

Quantification of sialic acid. Since the ganglioside samples were reacetylated after hydrolysis, it was not possible to determine by GLC whether $N$-glycolylneuraminic acid was present. However, none was detectable in samples kindly analyzed for us by Dr. Robert Ledeen (19). This confirms the findings of Madoff, Ebbe, and Baldini (35). The $N$-acetyl neuraminic acid (NANA) content of whole platelets was $7.8 \pm 0.7 \mu \mathrm{g} / \mathrm{mg}$ platelet protein, as determined by the resorcinol method (corrected at $450 \mathrm{~m} \mu$ for hexoses) (9). A comparison of our results as obtained by several different techniques is shown in Table I. Samples analyzed from platelet concentrates derived from bank blood usually gave slightly higher values than those from individual donors.

The quantity of lipid-bound neuraminic acid (which by definition is ganglioside) was then related to the total platelet NANA. This amounted to $6 \%$. In four separate experiments the ganglioside content was also related to total platelet lipid as obtained by a factor derived from lipid phosphorus values (18). Thus, gangliosides comprise an average of $0.5 \%$ of platelet lipids by weight (36).

Identification of platelet gangliosides. Qualitative analyses were initially carried out in the chloroformmethanol-ammonium hydroxide solvent system (19). The three major components found are depicted in Fig. 1. These have been arbitrarily defined in accordance with

\footnotetext{
${ }^{18}$ Glucostat, Worthington Biochemical Corp., Freehold,
} N. J. 


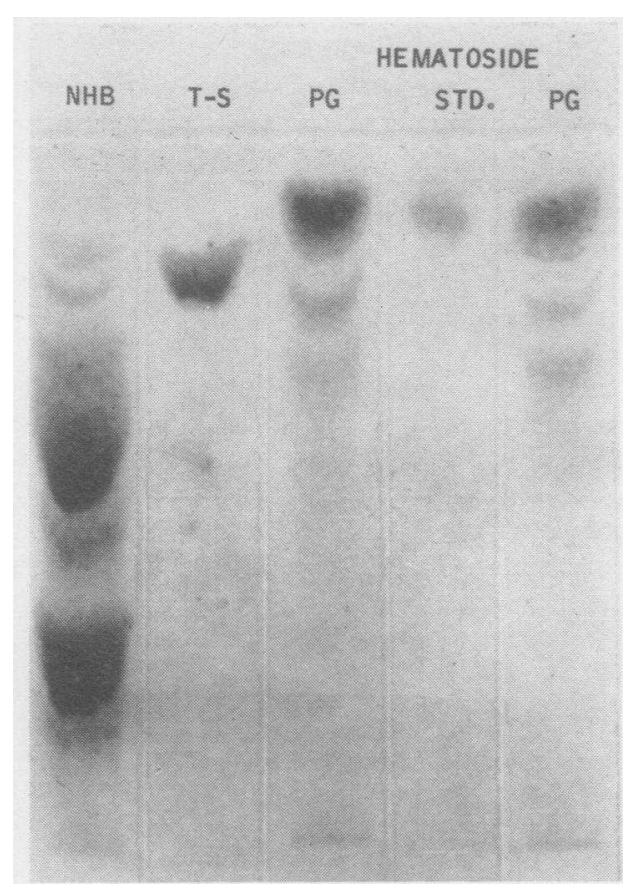

FIGURE 1 Thin-layer chromatogram of various gangliosides (developing solvent chloroform-methanol-ammonium hydroxide on silica gel HR [19]). NHB, normal human brain; $\mathrm{T}-\mathrm{S}$, Tay-Sachs ganglioside; $\mathrm{PG}$, platelet gangliosides: hematoside std., hematoside standard. Note the virtual absence of brain-type gangliosides in platelets. The Tay-Sachs ganglioside was not detected in platelets. The platelet ganglioside with the highest $R_{f}$ was designated ganglioside $\mathrm{I}$. The second component was ganglioside II and the third, which was later shown to be heterogeneous, was called ganglioside III. Spray: resorcinol.

their chromatographic mobility as gangliosides I. II, and III. As will be shown, ganglioside I was identified as hematoside ( $\mathrm{G}_{6}, \mathrm{G}_{\mathbf{s} 3}$, sialosyllactosyl ceramide) (37). Quantitatively, hematoside comprised 92 moles/100 moles of platelet gangliosides. On the basis of its composition and neuraminidase susceptibility, ganglioside II $(5 \%)$ was designated Ga.nn1 (NANA) (ganglioside lacto- $N$ neotetraose), as originally described by Kuhn and Wiegandt (38) (two structural forms of this ganglioside have been noted [39]). However, it should be mentioned that ganglioside II contained galactosamine in addition to the predominant hexosamine. glucosamine. Ganglioside III $(2 \%)$ was subsequently found to contain $\mathrm{G}_{3 \mathrm{~A}}$ (disialosyllactosyl ceramide) (37) as well as two other components. As shown in Fig. 1, ganglioside III migrated as a single spot with some degree of trailing. It always cochromatographed with a $\mathrm{G}_{3 . .}$ standard prepared from beef kidney. However, in the propanol-water TLC system (silica gel G) two spots were found, one of which contained $\mathrm{G}_{3 \mathbf{s}}$. The second migrated with a $\mathrm{Gm}_{\mathrm{ma}}$ (Gs) standard (37). In a third system (chloroformmethanol-water) ganglioside III had three components, one of which was $\mathrm{G}_{3 \mathrm{~A}}$; another was chromatographically compatible with $\mathrm{G}_{\mathrm{Dla}}$, and the third spot may be an analogue of ganglioside II. The observation on TLC that ganglioside III was heterogeneous was confirmed by GLC and neuraminidase studies. In contrast, gangliosides I and II consistently migrated as single components in all TLC systems. Ganglioside I was also detected in isolated platelet granules and membranes.

TLC studies were carried out on concentrates from the lower phases of the ganglioside extraction mixtures. Neutral glycolipids, if present, would appear in this layer. The plates were sprayed with an orcinol-sulfuric acid reagent (40). Three well separated components were seen, one of which predominated and was identified as lactosyl ceramide by comparison with known standards. The two remaining fractions, which migrated below lactosyl ceramide, were not further investigated.

GLC analysis of platelet gangliosides. The use of temperature programming permitted identification of hexoses, hexosamines, NANA, and the long-chain sphingosine bases in a single chromatographic run. Ganglioside I (hematoside) contained galactose and glucose in a molar ratio of $1.07: 1 . N$-acetyl neuraminic acid

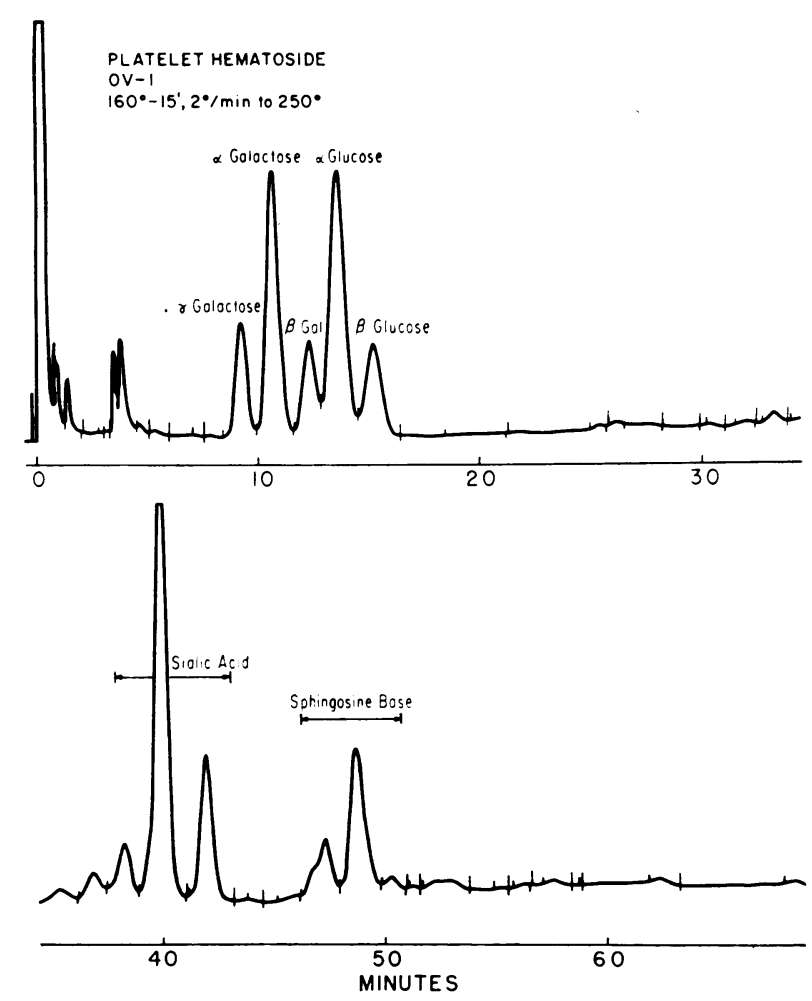

Figure 2 GLC analysis of carbohydrates, sialic acid, and sphingosine bases of platelet hematoside (ganglioside I). The absence of hexosamine and molar ratios of glucose: galactose: sialic acid: sphingosine base of $1: 1: 1: 1$ confirm the identity of hematoside. (Unlabeled peaks were artifacts.) 
was also present in a molar ratio of 1.07 to glucose and this was confirmed by colorimetric analysis. Hexosamines were undetectable in ganglioside I. The major longchain base was identified as sphingosine. A typical gasliquid chromatograph of these findings in ganglioside I is shown in Fig. 2. The results confirm the identity of the predominant platelet ganglioside as hematoside.

There was a preponderance of long-chain fatty acids in ganglioside I. The major component was behenate (22:0), which comprised $33.6 \%$ of the total. This was followed by nervonate $(24: 1), 18.7 \%$, and lignocerate $(24: 0), 14.8 \%$. Hematoside fatty acid methyl esters were also examined for the presence of hydroxy fatty acids (27), but none were found by TLC.

The carbohydrate composition of ganglioside II most closely resembled ganglioside GLNnr1 (NANA) (lacto$N$-neotetraose) $(38,41)$. The components present and their molar ratios with respect to glucose were: galactose (1.88), NANA (0.88), long-chain base (0.92), hexosamines $(0.94)$. The major hexosamine was glucosamine $(72 \%)$. Galactosamine $(28 \%)$ was also present.

In contrast to hematoside, ganglioside II was characterized by the presence of palmitic acid $(31.2 \%)$. However, the long-chain fatty acid pattern was somewhat similar-behenate $(17.0 \%)$, lignocerate $(9.2 \%)$, and nervonate $(20.0 \%)$.

GLC analyses of ganglioside III were not compatible with integral ratios of the carbohydrate components. Rather, the ratios suggested the presence of a mixture of gangliosides. This prompted reinvestigation of the fraction by two other TLC systems which indeed demonstrated three components. Nevertheless, the carbohydrate ratios obtained indicated the presence of multiple sialic acid units. The hexosamines present were glucosamine $(73 \%)$ and galactosamine $(27 \%)$. Palmitate $(16: 0)$ predominated in the ganglioside III mixture $(54.5 \%)$. Most notable otherwise was the presence of relatively short-chain fatty acids as compared to gangliosides I and II.

The results of GLC analyses of the carbohydrates and fatty acids in gangliosides I, II, and III are summarized in Tables II and III. As in hematoside, the major longchain base in gangliosides II and III was sphingosine.

Neuraminidase reaction with platelet gangliosides. Assays of free sialic acid after neuraminidase treatment

TABLE II

Carbohydrate Composition of Platelet Gangliosides* $\ddagger$

\begin{tabular}{|c|c|c|c|c|}
\hline Ganglioside & Glucose & Galactose & NANA & Hexosamine \\
\hline I (hematoside) & 1.0 & 1.07 & 1.07 & 0 \\
\hline II (lacto- $N$-neotetraose) & 1.0 & 1.88 & 0.88 & 0.94 \\
\hline III & 1.0 & 1.76 & 1.51 & 0.72 \\
\hline
\end{tabular}

* Molar ratios, relative to glucose as 1 .

$\ddagger$ As determined by GLC.
TABLE III

Fatty Acid Compositions of Platelet Gangliosides*

\begin{tabular}{cccc}
\hline & \multicolumn{3}{c}{ Gangliosides } \\
\cline { 2 - 4 } Fatty acid & I (hematoside) $¥ \begin{array}{l}\text { II (lacto- } N \text { - } \\
\text { neotetraose) } \ddagger\end{array}$ & III $¥$ \\
\hline $12: 0$ & 0.3 & & 0.4 \\
$14: 0$ & 0.2 & 1.7 & 4.6 \\
$15: 0$ & 0.1 & 0.5 & 2.2 \\
$16: 0$ & 7.7 & 31.2 & 54.5 \\
$16: 1$ & & 1.6 & 3.9 \\
$17: 0$ & 0.2 & 0.5 & 1.3 \\
$18: 0$ & 2.3 & & 7.8 \\
$18: 1$ & & 0.1 & 4.2 \\
$20: 0$ & 7.8 & 3.4 & 1.7 \\
$20: 1$ & 1.1 & 0.6 & 0.5 \\
$20: 2$ & 0.2 & 2.0 & 4.4 \\
$21: 0$ & 0.5 & & \\
$22: 0$ & 33.6 & 17.0 & 3.7 \\
$22: 1$ & 6.7 & 5.0 & 1.3 \\
$23: 0$ & 3.3 & 1.8 & 0.7 \\
$23: 1$ & 0.7 & 1.2 & 0.4 \\
$24: 0$ & 14.8 & 9.2 & 2.2 \\
$24: 1$ & 18.7 & 20.0 & 5.1 \\
$24: 2$ & 1.6 & 1.9 & 0.4 \\
\hline
\end{tabular}

* Weight per cent of fatty acids.

$\ddagger$ Representative figures from two separate hematoside isolations. Analyses of gangliosides II and III represent single isolations.

indicated that gangliosides I, II, and III were susceptible to the action of the enzyme. In all instances free NANA recoveries were close to $100 \%$. The reaction product obtained from hematoside was lactosyl ceramide, which further confirmed its identity. The results of this experiment are depicted in Fig. 3. Experiments with gangliosides II and III were more difficult to evaluate and had to be interpreted in conjunction with the GLC and TLC data. The product of ganglioside II showed no definite resorcinol staining spots other than free NANA, which was in agreement with the TBA assay. The one major cleavage product was an orcinol positive spot on TLC. This component was presumed to be a ceramide tetrahexoside although it did not cochromatograph with a standard marker. The standard (galactosyl- $N$-acetylgalactosaminyllactosyl ceramide) was prepared in our laboratory fram bovine brain gangliosides and did not contain glucosamine. Since glucosamine is present in ganglioside II it may have influenced the chromatographic mobility of the neuraminidase product. However, subsequent GLC analysis verified its identity as a ceramide tetrahexoside.

In the case of ganglioside III, lactosyl ceramide was a major cleavage product as found by TLC and GLC. This confirmed the presence of $\mathrm{G}_{3 \mathrm{~A}}$. In addition, a component with the same $R_{f}$ value as the ceramide tetrahexoside 


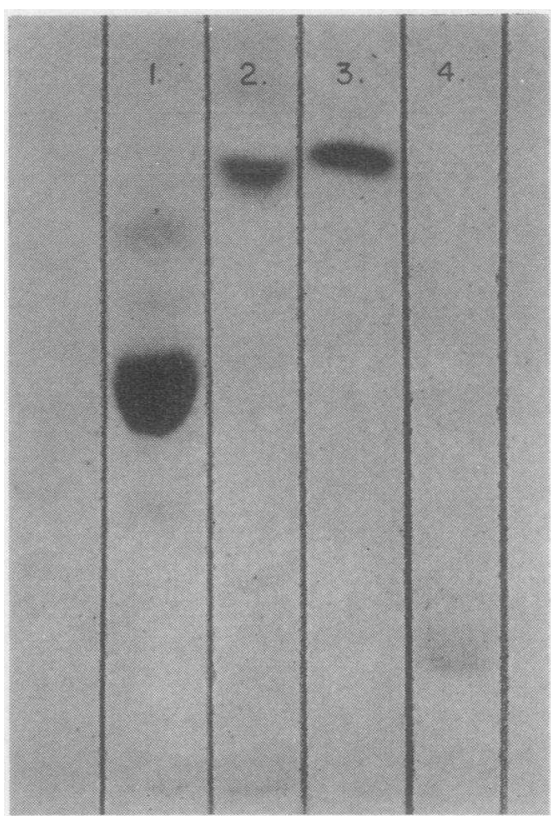

FigLRE 3 TLC of ganglioside I (hematoside) before and after treatment with neuraminidase from $\mathrm{Cl}$. perfringens. Components of each lane are as follows: (1) untreated ganglioside I; (2) neuraminidase-treated ganglioside I; (3) lactosyl ceramide standard; (4) NANA standard. Silica gel HR plate sprayed with orcinol-sulfuric acid reagent.

from ganglioside II was found. This suggested that ganglioside III contained in addition to $\mathrm{G}_{3 s}$ an analogue of ganglioside II. The demonstration of glucosamine and the high content of galactose by GLC provides supporting evidence for the above conclusions.

Equilibrium dialysis studics. When serotonin $-{ }^{14} \mathrm{C}$ was dialyzed against buffer blanks or distilled water, it reached equilibrium after $24 \mathrm{hr}$. Typical counts were $22,911 \mathrm{cpm} / 25 \mu \mathrm{l}$ on one side of the membrane versus $22,770 \mathrm{cpm}$ on the other. Lecithin, the major phospholipid of platelet membranes (18), was virtually incapable of binding 5-HT. The predominant neutral lipid of platelet membranes, cholesterol (18), took up no serotonin whatever. Egg lysolecithin, which was studied because of its solubility properties, was also negative. Platelet gangliosides I and III unequivocally bound small amounts of 5-HT, as evidenced by persistence of a significant difference in counts on the two sides of the chamber for over $330 \mathrm{hr}$. Isolated control gangliosides $\mathrm{G}_{\mathrm{o}}$ and $\mathrm{G}_{3 \mathbf{s}}$ from beef kidney as well as bovine brain ganglioside $G_{M 1}$ (1) (commercially obtained) also gave positive results. An example of 24-hr counts with platelet ganglioside III is : ganglioside III, $25,832 \mathrm{cpm} / 25 \mu 1$ as against $23,150 \mathrm{cpm} /$ $25 \mu 1$ in the opposite chamber. The results are summarized in Table IV.

Experiments were subsequently carried out in an attempt to modify and/or reverse the binding interactions which took place. In order to remove most of the free serotonin, the dialysis system was reversed by repeatedly replacing the contents of the chamber opposite that containing the test material with fresh buffer and allowing the system to equilibrate. This was done until the counts in this chamber were reduced to less than $250 \mathrm{cpm} / 25 \mu \mathrm{l}$ portion. There was little or no reduction in the counts that had been originally bound to the lipid samples. In the case of a control, such as lysolecithin, the relatively insignificant amounts of serotonin which did bind could be virtually removed by reverse dialysis. Addition of calcium or reserpine to the dialysis system had no effect on the results, and when EDTA was used it directly bound $5-\mathrm{HT}$ in the control samples. Inclusion of an energy source such as ATP was not possible since this nucleotide directly complexes with serotonin (42). Furthermore, several of the lipids evaluated for serotonin binding were converted to their acid form by treatment with Dowex 50 $\left(\mathrm{H}^{+}\right.$form $)$, but the 5-HT interactions were not altered.

At the conclusion of several dialysis exeriments samples of human platelet ganglioside III, ganglioside I, bovine brain $\mathrm{G}_{\mathrm{M} 1}$, and serotonin- ${ }^{14} \mathrm{C}$ controls were subjected to ultracentrifugation (see Methods). The extent of binding before ultracentrifugation was determined by the final difference in counts between the two sides of the cell. In all instances except the serotonin control the highest concentration of bound radioactivity sedimented to the bottom of the ultracentrifuge tube, and this was positively correlated with assays for sialic acid content. The results were particularly striking in the case of platelet gangliosides III and I and are summarized in Table V.

The sedimented ganglioside III from the ultracentrifuge experiments was then subjected to TLC along with cold 5-HT and serotonin $-{ }^{14} \mathrm{C}$ controls (as described in Methods). It was found that $77 \%$ of the bound radioac-

TABLE IV

Binding of Serotonin by Gangliosides and Other Lipids*

\begin{tabular}{|c|c|}
\hline Lipid & $\begin{array}{c}\text { Dialysis } \\
24 \mathrm{hr}\end{array}$ \\
\hline & $\begin{array}{c}\text { moles } \\
\text { lipid/mole } \\
\text { serotonin }{ }^{-14} C\end{array}$ \\
\hline Human platelet ganglioside III & 103 \\
\hline Human platelet ganglioside I (hematoside) & 218 \\
\hline Beef kidney $\mathrm{G}_{3 \mathrm{~A}}$ & 40 \\
\hline Beef kidney $\mathrm{G}_{6}$ (hematoside) & 133 \\
\hline Human platelet lecithin & 1237 \\
\hline Human platelet cholesterol & None \\
\hline Egg lysolecithin & 768 \\
\hline Bovine brain $\mathrm{G}_{\mathrm{M} 1}$ & 259 \\
\hline
\end{tabular}

* Results are expressed as moles of lipid required to bind 1 mole of serotonin-14 $\mathrm{C}$. 
tivity remained at the origin of the plate in the lipid spot, and the serotonin controls had migrated to the vicinity of the solvent front. It was thus concluded that the radioactivity originally bound by the ganglioside in the dialysis chamber had persisted throughout the ultracentrifugation and TLC procedures.

\section{DISCUSSION}

The sialic acid content of whole platelets is $7.8 \pm 0.7 \mu \mathrm{g} /$ $\mathrm{mg}$ platelet protein. This is less than the figure of $\mathbf{1 5 . 5}$ $\mu \mathrm{g}$ reported by Madoff and associates (35). Since precise quantification of sialic acid was important for the ganglioside studies, techniques for measuring NANA and factors influencing the results were investigated in detail. As shown in Table $I$, the values obtained by several methods for NANA measurement were consistent. As an additional control, several units of platelets were processed as described by Madoff and coworkers (35), but this had no effect on the results. $6 \%$ of the total platelet neuraminic acid was lipid-bound. This figure is comparable to those obtained by Puro, Maury, and Huttunen (2-8\%) in a survey of the ganglioside content of eight extraneural tissues of the rat, rabbit, and pig (2). It is in marked contrast to brain tissue, where more than $50 \%$ of the NANA is lipid-bound (2).

Ganglioside I (hematoside) comprised $92 \%$ of the total platelet gangliosides. Its identification was confirmed by TLC, GLC, and neuraminidase studies. Hematoside is the major extraneural ganglioside (19) and its presence in a wide variety of tissues has been reported (43). For example, $92 \%$ of bovine adrenal medulla gangliosides are hematosides (19). In fact, the term "hematoside" was first coined by Yamakawa and Suzuki when they isolated this glycosphingolipid from equine erythrocytes (44). Our finding of hematoside as the major platelet ganglioside (45) has recently been confirmed by Tao, Jamieson, and Sweeley (46). The fatty acid composition of ganglioside I was comparable to that of other extraneural hematosides (27). Long-chain fatty acids such as behenate $(33.6 \%)$ predominated.

Ganglioside II, which represented $5 \%$ of platelet gangliosides, is a relatively novel glycosphingolipid. It was first described in bovine erythrocytes and spleen (38), and more recently Dawson (47) has identified a ganglioside with similar components in human erythrocytes. Furthermore, Etzrodt (30) found ganglioside lacto- $N$ neotetraose in bovine platelets. Relatively large amounts of ganglioside II were required for its chemical identification, and insufficient quantities remained for use in the serotonin binding studies. In contrast to ganglioside I, large amounts of palmitic acid were found in ganglioside II.

Ganglioside III ( $2 \%$ of platelet gangliosides) was initially identified as $\mathrm{G}_{3 \mathrm{~s}}$. Although the neuraminidase stud-
TABLE V

Ultracentrifugation of Platelet Ganglioside-Bound Serotonin-14 C

\begin{tabular}{|c|c|c|c|c|c|}
\hline & \multirow{2}{*}{$\frac{\text { Control }}{\text { Counts }}$} & \multicolumn{2}{|c|}{ Ganglioside III } & \multicolumn{2}{|c|}{$\begin{array}{r}\text { Ganglioside I } \\
\text { (hematoside) }\end{array}$} \\
\hline & & Counts* & NANA & Counts* & NANAf \\
\hline A (top) $\S$ & 20.1 & 3.9 & 3.9 & 3.1 & 2.9 \\
\hline B & 20.2 & 3.3 & 3.9 & 3.0 & 2.9 \\
\hline C & 19.8 & 3.3 & 3.9 & 3.8 & 3.8 \\
\hline D & 19.9 & 3.8 & 4.7 & 3.1 & 4.9 \\
\hline E (pellet) & 20.1 & 85.7 & 83.5 & 87.1 & 85.4 \\
\hline
\end{tabular}

* Per cent of total recovered bound counts.

$\ddagger$ Per cent of total recovered NANA.

Details of experiment are given in Methods.

ies verified the presence of $\mathrm{G}_{3 \Delta}$, these experiments as well as GLC and subsequent TLC analyses demonstrated two other components. Further qualitative and quantitative analysis on this fraction was not feasible because of the minute quantities involved. Nevertheless, it was felt that the presence of $\mathrm{G}_{3 \mathrm{~s}}$ in ganglioside III justified the use of this fraction in the 5-HT binding studies.

When concentrates derived from the lower phases of the ganglioside extractions were examined by TLC, three neutral glycolipid components were found. The major fraction was identified as lactosyl ceramide. The other two more slowly migrating components were not identified due to lack of appropriate standards. The finding of lactosyl ceramide is in agreement with recent reports by Hildebrand, Stryckmans, and Stoffyn (48) and Tao et al. (46).

Several previous lines of investigation indicated that a study of platelet gangliosides with particular reference to a possible interaction with serotonin would be of great interest. Platelets can take up 5-HT by an active transport mechanism at $37^{\circ} \mathrm{C}$ and by passive diffusion and adsorption at $2^{\circ} \mathrm{C}(49)$. Baumgartner and Born (50) have proposed that serotonin is bound to a specific receptor on the outer surface of the platelet membrane. The receptor is part of a "carrier system" that functions to move 5-HT to the inner portion of the membrane. Serotonin is then either metabolized in the platelet cytoplasm or taken up by specific storage organelles. The precise nature of the 5-HT receptor has been a subject of interest for several years. Woolley and Gommi (51) presented evidence that gangliosides, and in particular $\mathrm{G}_{3 \wedge}$, could bind 5-HT as measured by two techniques of bioassay. Treatment of the serotonin-susceptible tissue with purified neuraminidase (and EDTA) rendered it insensitive to the action of $5-\mathrm{HT}$. Restoration of 5-HT responsiveness could be achieved by treatment with a purified ganglioside preparation. Van Heyningen (52) demonstrated that gangliosides in aqueous media could bind 5-HT as well as other pharmacologic agents such as lysergic acid diethylamide and chlorpromazine. Gielen 
$(53,54)$ dialysed serotonin against purified ganglioside $\mathrm{G}_{3 .}$ and observed the formation of a ganglioside-serotonin complex which was stable at $4^{\circ} \mathrm{C}$. The ganglioside, in an aqueous medium, had been mixed with equimolar amounts of $5-\mathrm{HT}$. After $1 \mathrm{wk}$ of dialysis, $70 \%$ of the added serotonin was present in the bag with the lipid as measured spectrofluorometrically. Etzrodt (30) made a detailed study of the 5-HT-binding properties of gangliosides in a dialysis system. The total ganglioside fraction from bovine platelets could bind $5-\mathrm{HT}$, but individual bovine platelet gangliosides were not studied because components such as $\mathrm{G}_{3 .}$ were present in infinitesimal amounts. Thus, ganglioside $\mathrm{G}_{3 \mathrm{~s}}$ from a more abundant source such as cat erythrocytes was subsequently studied, and a binding ratio of 5 moles of ganglioside to 1 mole of serotonin was achieved. In our experiments this degree of binding could not be attained. The binding ratio for human platelet ganglioside III was 103 moles of ganglioside per 1 mole of serotonin $-{ }^{14} \mathrm{C}$. The binding with beef kidney $\mathrm{G}_{3 A}$ in our system was 40 moles per 1 mole of serotonin $-{ }^{14} \mathrm{C}$. The reasons for these differences are not readily apparent. Among the possibilities are: (a) We used radioactive serotonin rather than spectrofluorometry. (b) Human platelet gangliosides may require an additional cofactor for serotonin binding which perhaps was lost during purification or not present in the dialysis system. (c) Since limited amounts of human gangliosides were available for study, the dialysis system could not be evaluated under widely varying conditions.

As already shown by Born and Bricknell (49), platelets take up serotonin $-{ }^{14} \mathrm{C}$ in the cold, but to a much lesser extent than at $37^{\circ} \mathrm{C}$. The uptake at $2^{\circ} \mathrm{C}$ is due to diffusion or adsorption. Thus, the mechanism by which small amounts of radioactive 5 -HT become associated with platelets at $2^{\circ} \mathrm{C}$ is different from the active transport process which predominates at $37^{\circ} \mathrm{C}$. The interactions we have demonstrated between 5-HT and human platelet gangliosides could have taken place by the same mechanism. It was necessary to carry out our experiments at $4^{\circ} \mathrm{C}$ since at $37^{\circ} \mathrm{C}$ isolated gangliosides tend to lose their micellar configuration, thereby allowing passage through the dialysis membrane.

It should be mentioned that the concept of gangliosides as serotonin receptors has recently been challenged. De Robertis (55) and Fiszer and De Robertis (56) have purified a proteolipid from brain showing high affinity for substances such as 5-HT and d-tubocurarine which they termed "receptor proteolipid." We have demonstrated the presence of proteolipid in whole platelets, platelet granules, and membranes (18). Studies of platelet proteolipid interactions with serotonin are currently in progress.

Our data cannot be interpreted to indicate that platelet gangliosides are the "receptors" or "acceptors" (57) for
5-HT. The attachment of serotonin- $-{ }^{14} \mathrm{C}$ to platelet gangliosides was demonstrated, but only in small amounts. However, such binding was absent when other platelet lipid controls were similarly tested. Nevertheless, our experimental results did not confirm the data and interpretations previously reported in the literature for ganglioside-serotonin interactions.

Results of the neuraminidase experiments indicated that isolated platelet gangliosides were susceptible to the action of the enzyme from $\mathrm{Cl}$. perfringcns. Theoretically, therefore, treatment of whole platelets with this enzyme should release virtually all of the lipid-bound sialic acid which represents $6 \%$ of the total platelet NANA. Madoff and associates (35) reported that $74 \%$ of the total sialic acid of frozen and thawed platelets was liberated by neuraminidase. Barber and Jamieson (5) treated two platelet membrane fractions with neuraminidase and observed release of 68 and $70 \%$ of the total NANA, respectively. Although it was possible that part of the unsusceptible fraction of sialic acid was present in gangliosides, this would appear to be unlikely. However, as Weinstein, Marsh, Glick, and Warren (58) have pointed out, gangliosides in the cell membrane may be oriented in a manner which renders them inaccessible to neuraminidase. Thus the precise identity of the neuraminidase-resistant fraction of whole platelet sialic acid remains to be determined.

The development of interest in extraneural gangliosides is relatively recent and is due in large part to advanced techniques of microanalysis $(1,58,59)$. There is now general agreement that glycosphingolipids are plasma membrane components and contribute to the organization and function of the cell surface in an important manner $(59,60,3)$. As emphasized by Lehninger (3), the relatively low content of gangliosides in certain tissues does not diminish the possible importance of their role in cell interactions. The negatively charged sialic acid termini of gangliosides may protrude through the "cell coat" from specific locations in the plasma membrane and provide a reactive site in the extracellular milieu (3).

Since many important and as yet incompletely understood platelet functions appear to be "membrane surface phenomena" (61), it is suggested that platelet gangliosides, appropriately oriented in the plasma membrane, may be important constituents in some of these interactions.

Addendum. Since our manuscript was submitted for publication another paper has come to our attention (62) in which the presence of hematoside was reported in human platelets.

\section{ACKNOWLEDGMENTS}

We wish to thank Doctors Robert Ledeen and Robert Yu for many helpful discussions in the course of this work. 
Appreciation is also expressed to the New York Blood Center for supplying us with platelets for use in these studies.

This study was supported by grants from the Veterans Administration, the National Institutes of Health (HE09070-08), the New York Heart Association, and the S. M. Louis Memorial Fund for Research in Thrombosis and Atherosclerosis.

\section{REFERENCES}

1. Ledeen, R. 1966. The chemistry of gangliosides: a review. J. Am. Oil Chem. Soc. 43: 57.

2. Puro, K., P. Maury, and J. K. Huttunen. 1969. Qualitative and quantitative patterns of gangliosides in extraneural tissues. Biochim. Biophys. Acta. 187: 230.

3. Lehninger, A. L. 1968. The neuronal membrane. Proc. Natl. Acad. Sci. U. S. A. 60: 1069.

4. Rasmussen, H. 1970. Cell communication, calcium ion, and cyclic adenosine monophosphate. Science (Wash. D. C.). 170: 404.

5. Barber, A. J., and G. A. Jamieson. 1971. Isolation of glycopeptides from low- and high-density platelet plasma membranes. Biochemistry. 10: 4711.

6. Ginsburg, V., and A. Kobata. 1971. Structure and function of surface components of mammalian cells. In Structure and Function of Biological Membranes. L. I. Rothfield, editor. Academic Press Inc., New York. 439.

7. Marcus, A. J., D. Zucker-Franklin, L. B. Safier, and H. L. Ullman. 1966. Studies on human platelet granules and membranes. J. Clin. Invest. $45: 14$.

8. Warren, L. 1959. The thiobarbituric acid assay of sialic acids. J. Biol. Chem. 234 : 1971.

9. Svennerholm, L. 1963. Sialic acids and derivatives: estimation by the ion-exchange method. Methods $E_{n}$ zymol. 6 : 459.

10. Svennerholm, L. 1963. Chromatographic separation of human brain gangliosides. J. Neurochem. 10: 613 .

11. Kean, E. L. 1966. Separation of gluco- and galactocerebrosides by means of borate thin-layer chromatography. J. Lipid Res. 7 : 449.

12. Suzuki, K. 1964. A simple and accurate micromethod for quantitative determination of ganglioside patterns. Life Sci. 3: 1227.

13. Suzuki, K. 1965. The pattern of mammalian brain gangliosides. II. Evaluation of the extraction procedures, post-mortem changes and the effect of formalin preservation. J. Neurochem. 12: 629 .

14. MacMillan, V. H., and J. R. Wherrett. 1969. A modified procedure for the analysis of mixtures of tissue gangliosides. J. Neurochem. 16: 1621.

15. Spiro, R. G. 1966. Analysis of sugars found in glycoproteins. Methods Enzymol. 8: 3.

16. Folch, J., M. Lees, and G. H. Sloane Stanley. 1957. A simple method for the isolation and purification of total lipides from animal tissues. J. Biol. Chem. 226: 497.

17. Puro, K. 1970. Isolation of bovine kidney gangliosides. Acta Chem. Scand. 24: 13.

18. Marcus, A. J., H. L. Ullman, and L. B. Safier. 1969. Lipid composition of subcellular particles of human blood platelets. J. Lipid Res. 10: 108.

19. Ledeen, R., K. Salsman, and M. Cabrera. 1968. Gangliosides of bovine adrenal medulla. Biochemistry. 7: 2287.

20. Wherrett, J. R., J. A. Lowden, and L. S. Wolfe. 1964. Studies on brain gangliosides. II. Analysis of human brain ganglioside fractions obtained by preparative thinlayer chromatography. Can. J. Biochem. 42: 1057.
21. Penick, R. J., M. H. Meisler, and R. H. McCluer. 1966. Thin-layer chromatographic studies of human brain gangliosides. Biochim. Biophy's. Acta. 116: 279.

22. Sweeley, C. C., and B. Walker. 1964. Determination of carbohydrates in glycolipides and gangliosides by gas chromatography. Anal. Chem. 36: 1461.

23. Kishimoto, Y., and N. S. Radin. 1965. A reaction tube for methanolysis; instability of hydrogen chloride in methanol. J. Lipid Res. $6: 435$.

24. Windeler, A. S., and G. L. Feldman. 1969. Silver acetate for stabilizing methyl galactosides after methanolysis of glycolipids. Lipids. $4: 167$.

25. Carter, H. E., and R. C. Gaver. 1967. Improved reagent for trimethylsilylation of sphingolipid bases. $J$. Lipid Res. 8 : 391.

26. Marcus, A. J., H. L. Ullman, L. B. Safier, and H. S. Ballard. 1962. Platelet phosphatides. Their fatty acid and aldehyde composition and activity in different clotting systems. J. Clin. Invest. 41: 2198.

27. Ledeen, R., and K. Salsman. 1970. Fatty acid and long chain base composition of adrenal medulla gangliosides. Lipids. $5: 751$.

28. Yu, R. K., and R. W. Ledeen. 1972. Gangliosides of human bovine and rabbit plasma. J. Lipid Res. 13: Sept.

29. Marchbanks, R. M. 1966. Serotonin binding to nerve ending particles and other preparations from rat brain. J. Neurochom. 13: 1481 .

30. Etzrodt, H. 1968. Über die glycolipoide der thrombozyten und die funktion eines thrombozytengangliosides als serotonin-rezeptor. Dostorate Thesis. University of Köln.

31. Parker, F., and N. F. Peterson. 1965. Quantitative analysis of phospholipids and phospholipid fatty acids from silica gel thin-layer chromatograms. J. Lipid Res. 6: 455.

32. Handa, S., and R. M. Burton. 1969. Lipids of retina. I. Analysis of gangliosides in beef retina by thin layer chromatography. Lipids. 4: 205.

33. Vance, W. R., C. P. Shook III, and J. M. McKibbin. 1966. The glycolipids of dog intestine. Biochemistry. 5: 435.

34. Vance, D. E., and C. C. Sweeley. 1967. Quantitative determination of the neutral glycosyl ceramides in human blood. J. Lipid Res. 8: 621 .

35. Madoff, M. A., S. Ebbe, and M. Baldini. 1964. Sialic acid of human blood platelets. J. Clin. Invest. 43: 870.

36. Marcus, A. J., L. B. Safier, and H. L. Ullman. 1972. The lipids of human platelets. In Blood Lipids and Lipoproteins. G. Nelson, editor. John Wiley \& Sons, Inc., New York. 417.

37. McCluer, R. H. 1970. Chemistry of gangliosides. Chem. Phys. Lipids. 5: 220.

38. Kuhn, R., and H. Wiegandt. 1964. ¿̈ber ein glucosaminhaltiges gangliosid. Z. Naturforsch. Teil B. 19b: 80 .

39. Wiegandt, H. 1970. Gangliosides of extraneuronal tissue. Chem. Phy's. Lipids. 5: 198.

40. Skipski, V. P., A. F. Smolowe, and M. Barclay. 1967. Separation of neutral glycosphingolipids and sulfatides by thin-layer chromatography. J. Lipid Res. 8: 295.

41. Wiegandt, H. 1968. The structure and the function of gangliosides. Angezv. Chem. Int. Ed. Engl. 7: 87.

42. Berneis, K. H., M. Da Prada, and A. Pletscher. 1969. Micelle formation between 5-hydroxytryptamine and adenosine triphosphate in platelet storage organelles. Science (Wash. D. C.). 165: 913. 
43. Svennerholm, L. 1964. The gangliosides. J. Lipid Res. $5: 145$.

44. Yamakawa, T., and S. Suzuki. 1951. The chemistry of the lipids of posthemolytic residue or stroma of erythrocytes. I. Concerning the ether-insoluble lipids of lyophilized horse blood stroma. J. Biochem. (Tokyo). 38: 199.

45. Marcus, A. J., H. L. Ullman, L. B. Safier, and H. S. Ballard. 1970. Studies on human platelet gangliosides. Fed. Proc. 29: 315. (Abstr.)

46. Tao, R. V. P., G. A. Jamieson, and C. C. Sweeley. 1972. Human platelet sphingolipids. Fed. Proc. 31: 913. (Abstr.)

47. Dawson, G. 1972. Glycosphingolipid levels in an unusual neurovisceral storage disease characterized by lactosylceramide galactosyl hydrolase deficiency: lactosylceramidosis. J. Lipid Res. 13: 207.

48. Hildebrand, J., P. Stryckmans, and P. Stoffyn. 1971. Neutral glycolipids in leukemic and nonleukemic leukocytes. J. Lipid Res. 12: 361.

49. Born, G. V. R., and J. Bricknell. 1959. The uptake of 5-hydroxytryptamine by blood platelets in the cold. J. Physiol. (Lond.). $147: 153$.

50. Baumgartner, H. R., and G. V. R. Born. 1969. The relation between the 5-hydroxytryptamine content and aggregation of rabbit platelets. J. Physiol. (Lond.) 201: 397.

51. Woolley, D. W., and B. W. Gommi. 1965. Serotonin receptors. VII. Activities of various pure gangliosides as the receptors. Proc. Natl. Acad. Sci. U.S. A. 53: 959.

52. Van Heyningen, W. E. 1963. The fixation of tetanus toxin, strychnine, serotonin and other substances by ganglioside. J. Gen. Microbiol. 31: 375.

53. Gielen, W. 1966. Über die funktion von gangliosiden. Ein serotonin-und $\mathrm{Ca}++$-receptor. Z. Naturforsch. Teil B. $21 \mathrm{~b}: 1007$.

54. Gielen, W. 1968. Über die funktion von gangliosiden. Die verbreitung des serotonin-receptors. Z. Naturforsch. Teil B. 23b: 117 .

55. De Robertis, E. 1971. Molecular biology of synaptic receptors. Science (Wash. D. C.). 171: 963.

56. Fiszer, S., and E. De Robertis. 1969. Subcellular distribution and chemical nature of the receptor for 5-hydroxytryptamine in the central nervous system. $J$. Neurochem. 16: 1201 .

57. Alivisatos, S. G. A., F. Ungar, P. K. Seth, L. P. Levitt, A. J. Geroulis, and T. S. Meyer 1971. Receptors: localization and specificity of binding of serotonin in the central nervous system. Science (Wash. D. C.). $171: 809$.

58. Weinstein, D. B., J. B. Marsh, M. C. Glick, and L. Warren. 1970. Membranes of animal cells. VI. The glycolipids of the $\mathrm{L}$ cell and its surface membrane. $J$. Biol. Chem. 245: 3928.

59. Stoffel, W. 1971. Sphingolipids. Annu. Rev. Biochem. 40: 57.

60. Rapport, M. M., and L. Graf. 1969. Immunochemical reactions of lipids. Prog. Allergy. 13: 273.

61. Marcus, A. J. 1969. Platelet function. N. Engl. J. Med. 280: $1213,1278,1330$.

62. Snyder, P. D., Jr., R. J. Desnick, and W. Krivit. 1972. The glycosphingolipids and glycosyl hydrolases of human blood platelets. Biochem. Biophys. Res. Commun. 46: 1857. 